\title{
Editorial: Special Issue on Quality of Life among Children and Adolescents in Chinese Societies
}

\author{
Janet T. Y. Leung ${ }^{1}$ (D) Annis L.C. Fung ${ }^{2}$
}

Received: 31 December 2020 / Accepted: 3 January 2021 / Published online: 5 February 2021

(C) The International Society for Quality-of-Life Studies (ISQOLS) and Springer Nature B.V. 2021

Quality of life studies have gained momentum among scholars and researchers who show passion and concerns about human lives. Quality-of-life researchers examine different aspects of human system that may affect one's well-being (e.g., Diener, Oishi, \& Lucas, 2003; Höfer, Gander, Höge, \& Ruch, 2020; Shek \& Lin, 2017). Though culture has played an important role in determining the standards and correlates of quality of life attributes (Diener \& Suh, 2003), studies are dominant in the WEIRD (Western, educated, industrialized, rich, and democratic) societies (Nielsen, Haun, Kärtner, \& Legare, 2017), whereas researches in non-Western contexts are relatively minor in terms of number and impacts. There are two main reasons why quality of life research in Chinese contexts should deserve more academic attention. First, Chinese people constitute to approximately $18 \%$ of the world population (Shek, 2020), their quality of life is worthy to be examined. Second, Chinese culture is deeply rooted in the Confucian thought that focus on collectivism, familism and interdependence (Yeh \& Yang, 1997), which is entirely different from the Western culture where individualism, independence and personal values are stressed (Shek, 2010). Hence, the beliefs systems, social relations, lifestyles and behaviors of Chinese people may be different from those grown up under the Western culture, which affect one's quality of life. Yang (1999) argued that "naïve" borrowing of Western concepts may result in inhibition of native values, views and ways of thinking. Shek (2006) also puzzled about the compatibility of Western theories and research findings when applying to Chinese people. Hence, there is a need to conduct quality-of-life research in Chinese contexts.

One major focus of the Special Issue is the examination of child and adolescent wellbeing. Childhood and adolescence are important life stages in human development, as individuals engage with and learn from different social systems to develop their selves (Erikson, 1968). Indeed, child and adolescent wellbeing are important developmental

Janet T. Y. Leung

janet.leung@polyu.edu.hk

1 Department of Applied Social Sciences, The Hong Kong Polytechnic University, Hung Hom, Kowloon, Hong Kong

2 Department of Social and Behavioural Sciences, City University of Hong Kong, Kowloon, Hong Kong 
outcomes that should be researched. Sharing the same concern, child and adolescent studies are also dominated by Western researchers and theorists. For instance, the theoretical framework of positive youth development approach was large developed in Western contexts (Catalano et al., 2002), whereas components and theories related to positive youth development in non-Western contexts are less explored (Qi, Hua, Zhou, \& Shek, 2020; Shek, Dou, \& Zhu, 2019). Hence, we confine our focus of the Special Issue on examining quality of life attributes among children and adolescents in Chinese societies.

Based on the ecological perspectives, personal traits interact with the environment to affect one's wellbeing and development (Bronfenbrenner, 1979). The impacts of social environment are particularly important for children and adolescents, as they grow and develop under the nurturance of different social systems (such as family, peers, school etc.). The study conducted by Lin, Wang and $\mathrm{Li}$ in a sample of Chinese adolescents in mainland China presented the psychosocial pathways of personal traits and social environment in affecting hedonic well-being (indexed by life satisfaction, selfesteem, positive affect, and negative affect) among Chinese adolescents. Results showed that the search of meaning in life (SMIL) was a quality-of-life promotor of hedonic well-being, and social connectedness (indexed by parent-child communication and peer relationship) served as a mediator between the relationship of SMIL and hedonic well-being among Chinese adolescents. Moreover, Lo examined the associations personal attributes (indexed by self-efficacy and mindfulness) and family functioning with quality of life among Chinese adolescents. Results showed that selfefficacy and mindfulness were strong predictors, while family functioning was a weak predictor of adolescent quality of life. Both studies showed that personal factors including searching meaning in life, self-efficacy and mindfulness are crucial in enhancing quality of life among Chinese adolescents.

In addition, studies conducted by Leung and colleagues and $\mathrm{Ma}$ in this special issue examined how family, peers and/or school systems affect child and adolescent wellbeing, academic performance and behavior. In a longitudinal study of school children studying in Grade 4 to Grade 6 in Hong Kong, Leung and colleagues found that both parent-child relationship and peer relationship influenced children's happiness. Academic achievement served as the mediator that partially mediated the association of parent-child relationship with children's happiness, and fully mediated the effects of peer relationship on children's happiness. Ma reported similar findings among Chinese adolescents in Hong Kong. While academic performance and psychological well-being were linked to increased family conflict and friends' problem behavior, they were associated with better family and peer support. The findings of both studies lend support to the importance of family and peers in influencing child and adolescent psychosocial development in Chinese societies.

According to the Confucian thought that focuses on familism and interdependence (Yeh \& Yang, 1997), family is an important social system that shapes child and adolescent development. Parental nurturance enhances children and adolescent positive development and wellbeing, but at the same time, negative parental behavior also brings adverse effects to children and adolescent wellbeing. Specific to Chinese culture, Leung and Shek examined the interaction effects of perceived paternal and maternal sacrifice on affecting developmental outcomes among Chinese adolescents experiencing economic disadvantage in Hong Kong. They identified that paternal sacrifice 
strengthened the association of maternal sacrifice with adolescents' self-identity, selfdetermination and self-efficacy. In the same vein, in a study of 1710 secondary school students in Hong Kong, Kwan and Kwok found that adolescents who experienced childhood emotional abuse reported less happiness via the decrease of emotional intelligence. These studies assessed the familial factors that affect adolescent wellbeing and psychosocial development, as well as the mechanisms and conditions that alter the effects. Furthermore, divorce has become a social issue in both local and global contexts. The rising numbers of single-parent families and re-married families have attracted scholars to examine how family structure affects child and adolescent development. In an online survey of Chinese adolescents aged 11 to 18, Fung found that boys growing up in stepmother families were more reactively aggressive than those from intact families, and showed greater anxiety and depression than those growing up in intact families and single-mother families.

Adolescence is the stage characterized by storm and stress (Hall, 1904) where adolescents are exposed to higher risks of self-destructive and anti-social behaviors (Elliott, 2009). In this Special Issue, internet addiction, peer victimization and suicidal ideation and their relationships with adolescent quality of life are examined. Lu and Zhou in this special issue examined the effects of internet addiction on adolescents' emotions and the mediational role of emotional competence through which the association occurred. The findings showed a direct effect of internet addiction on adolescents' negative emotions, and an indirect effect via poor regulation of emotions. Furthermore, in a cross-sectional study of school children in Hong Kong, Fung showed that boys experienced more physical and verbal victimization than did girls. Regarding adolescent suicidal ideation, Low in this special issue showed significant positive relationship between parent-child conflict and suicidal ideation among Chinese adolescents in Hong Kong, and the relationship was mediated by adolescents' depression and anxiety. By examining negative effects of internet addiction on adolescent emotions, characteristics of teenagers who suffer from peer victimization, as well as the contributive factors of adolescent suicidal ideation and the underlying mechanism, more tailormade intervention programs will be designed and implemented for children and adolescents. To enhance adolescent wellbeing and positive development, evidencebased practice is necessary to determine whether the intervention programs are effective and beneficial for adolescents. In this special issue, two studies examining the effectiveness of intervention programs for adolescents are highlighted. Zhu and Shek in this special issue examined the effectiveness of a credit-bearing subject on service leadership implemented in a university in Hong Kong. Students showed enhancement in service leadership knowledge, attitude, and behavior after participating in the subject. Moreover, the subject further enhanced students' life satisfaction and positive developmental outcomes. In another study conducted by Tam in evaluating the effectiveness of social entrepreneurship intervention program to help disadvantaged youth suffering from unemployment, both quantitative and qualitive findings lent support to the benefits of social entrepreneurship in enhancing self-worthiness and career competence of disadvantaged young people. Both studies showed empirical evidence supporting the usefulness of the intervention models in enhancing positive development and wellbeing of teenagers, which provide important practical implications to social service practitioners and educators. 
We take this opportunity to express our heartfelt gratitude to those scholars and researchers who have given invaluable comments in reviewing the papers submitted for this special issue. They are Prof. Yuk-chung Chan, Prof. Jesús M. Ramírez, Prof. Siuming To, Dr. Luis Millana Cuevas, Dr. Lawrence Gerstein, Dr. Rebecca Kinsey, Dr. Sylvia Kwok, Dr. Bess Lam, Dr. Ben Li, Dr. Camilla Lo, Dr. Natalia E. Fares Otero, Dr. Carmen Ye and Dr. Wei Zhang. Their assistance and support constitute to the successful publication of the special issue.

\section{References}

Bronfenbrenner, U. (1979). The ecology of human development: Experiments by nature and design. Cambridge, MA: Harvard University Press.

Catalano, R. F., Berglund, M. L., Ryan, J. A. M., Lonczak, H. S., \& Hawkins, J. D. (2002). Positive youth development in the United States: Research findings on evaluation of positive youth development programs. Prevention and Treatment, 5(15), 1-111.

Diener, E., Oishi, S., \& Lucas, R. E. (2003). Personality, culture, and subjective well-being: Emotional and cognitive evaluations of life. Annual Review of Psychology, 54(1), 403-425.

Diener, E., \& Suh, E. M. (Eds.). (2003). Culture and subjective well-being. London: MIT Press.

Elliott, G. C. (2009). Family matters: The importance of mattering to family in adolescence. Hoboken, NJ: Wiley-Blackwell.

Hall, G. S. (1904). Adolescence: Its psychology and its relation to physiology, anthropology, sociology, sex, crime, religion, and education (Vols. I \& II). Englewood Cliffs, NJ: Prentice-Hall.

Höfer, S., Gander, F., Höge, T., \& Ruch, W. (2020). Character strengths, well-being, and health in educational and vocational settings. Applied Research in Quality of Life, 15(2), 301-306.

Nielsen, M., Haun, D., Kärtner, J., \& Legare, C. H. (2017). The persistent sampling bias in developmental psychology: A call to action. Journal of Experimental Child Psychology, 162, 31-38.

Qi, S., Hua, F., Zhou, Z., \& Shek, D. T. (2020). Trends of positive youth development publications (19952020): A Scientometric review. Applied Research in Quality of Life, 1-26.

Shek, D. T. L. (2006). Chinese family research: Puzzles, progress, paradigms, and policy implications. Journal of Family Issues, 27(3), 275-284.

Shek, D. T. (2010). Introduction: Quality of life of Chinese people in a changing world. Social Indicators Research, 95(3), 357-361.

Shek, D. T. (2020). Chinese adolescent research under COVID-19. Journal of Adolescent Health, 67(6), 733734.

Shek, D. T. L., Dou, D. Y., \& Zhu, X. Q. (2019). Positive youth development: Current perspectives. Adolescent Health Medicine and Therapeutics, 10, 131-141.

Shek, D. T., \& Lin, L. (2017). Trajectories of personal well-being attributes among high school students in Hong Kong. Applied Research in Quality of Life, 12(4), 841-866.

Yang, K. S. (1999). Towards an indigenous Chinese psychology: A selective review of methodological, theoretical, and empirical accomplishments. Chinese Journal of Psychology, 41(2), 181-211.

Yeh, M. H., \& Yang, K. S. (1997). Chinese familism: Conceptual analysis and empirical assessment. Bulletin of the Institute of Ethnology. Academia Sinica (Taiwan), 83, 169-225.

Publisher's Note Springer Nature remains neutral with regard to jurisdictional claims in published maps and institutional affiliations. 